The Geneva Papers on Risk and Insurance, 22 (No. 84, July 1997) 523-535

\title{
Efficiency and Productivity of the Insurance Industry in the OECD Countries
}

\author{
by Olivier Donni and Fabienne Fecher*
}

\begin{abstract}
The purpose of the paper is to measure technical efficiency levels in 15 OECD insurance industries over the period 1983-1991 and to decompose productivity changes into technical progress and efficiency variations. We show that the growth in the productivity observed in all countries is essentially imputable to improvements in technical progress. We then try to see whether some structural national characteristics of insurance markets can partly explain the differentials in efficiency levels across countries. Reinsurance rates and market shares in OECD both seem to favor efficiency levels. The study is a step towards a comprehensive efficiency comparative study of the OECD insurance markets especially desirable in this period of increasing integration and deregulation of the market.
\end{abstract}

\section{Introduction}

As the completion of the European internal market approaches, a number of countries are rightfully concerned with the efficiency of their insurance industries. In recent years, different empirical studies were conducted in this field. All, however, were based on individual firms' data and compared no more than two countries.

This paper is a step towards a comprehensive efficiency study of the insurance market. More precisely, we intend to compare the insurance market in the OECD countries from both a static and a dynamic point of view. In this respect, we measure technical efficiency levels reached by each OECD country over the period 1983-1991, using an intertemporal DEA method. In order to analyze the dynamic features, we decompose productivity changes into two components: technical progress and efficiency changes using the Malmquist index method. DEA and Malmquist methods are closely linked to the concept of frontier.

* Olivier Donni: University of Mons-Hainaut and CREPP, Belgium;

Fabienne Fechner: University of Liège and CREPP, Belgium.

The authors are grateful to Sergio Perelman and Pierre Pestieau for their comments and to Susanna Argiolas for a preliminary work on the data. This paper is part of a research program supported by the Belgian Fonds National de la Recherche Scientifique (FNRS No. 2.4537.90) and by Belgian Service de Programmation de la Politique Scientifique (SPPS No. 141). 
This frontier will be constructed using panel data and will be used as a yardstick of efficiency across countries. One should, however, realize that any increase in the number of countries has two main consequences. It necessitates the use of aggregate data and reduces the number of available variables.

In a second part of the paper, we try to see to what extent efficiency levels can be explained by different structural characteristics of the insurance market such as national and foreign market shares, average size of companies and the ratio of reinsurance accepted to total gross premiums. We also check whether or not there would be productivity growth in a very labor-intensive sector such as insurance industry.

The paper is organized as follows. In the next section, we present a survey of the literature and we discuss the concept of insurance service output. Section 3 sketches the methodology used to obtain the measure of efficiency level and the two components of productivity change. Section 4 is devoted to the presentation of the OECD data. Section 5 describes the main results concerning efficiency levels and productivity changes and presents the explanatory analysis. Conclusions are given in a final section.

\section{Empirical background}

In an individual firm's context, previous studies provide productive efficiency measures for samples of Belgian, French and U.S. life and non-life insurance companies. Those studies and their main results are summarized in Table 1.

Table 1: Insurance efficiency studies based on individual data

\begin{tabular}{|c|c|c|c|c|c|}
\hline Authors & Countries & Methods & Branches & Outputs & $\begin{array}{l}\text { Average } \\
\text { efficiency }\end{array}$ \\
\hline Cummins and Weiss (1993) & US & $\begin{array}{l}\text { Stochastic cost } \\
\text { frontier }\end{array}$ & $\begin{array}{l}\text { Property- } \\
\text { liability }\end{array}$ & Losses & $0.79-0.90$ \\
\hline Delhausse et al. (1995) & $\begin{array}{l}\text { Belgium and } \\
\text { France }\end{array}$ & $\begin{array}{c}\text { DEA and } \\
\text { production } \\
\text { stochastic frontier }\end{array}$ & Non-life & Gross premiums & $0.43-0.55$ \\
\hline Donni and Hamende (1993) & Belgium & $\begin{array}{c}\mathrm{FDH} \\
\text { intertemporal and } \\
\text { sequential }\end{array}$ & $\begin{array}{l}\text { Life and } \\
\text { non-life }\end{array}$ & $\begin{array}{l}\text { Gross premiums } \\
\text { and loss }\end{array}$ & $0.44-0.64$ \\
\hline Fecher et al. (1991) & France & $\begin{array}{l}\text { Deterministic cost } \\
\text { frontier }\end{array}$ & $\begin{array}{l}\text { Life and } \\
\text { non-life }\end{array}$ & $\begin{array}{l}\text { Gross premiums } \\
\text { and loss }\end{array}$ & $0.24-0.41$ \\
\hline Fecher et al. (1993) & France & $\begin{array}{c}\text { DEA and } \\
\text { production } \\
\text { stochastic frontier }\end{array}$ & $\begin{array}{l}\text { Life and } \\
\text { non-life }\end{array}$ & $\begin{array}{l}\text { Gross premiums } \\
\text { and financial } \\
\text { returns }\end{array}$ & $0.24-0.54$ \\
\hline Gardner and Grace (1993) & US & $\begin{array}{l}\text { Stochastic cost } \\
\text { frontier }\end{array}$ & Life & $\begin{array}{c}\text { Securities } \\
\text { investments, } \\
\text { Premiums and } \\
\text { Annuities }\end{array}$ & 0.45 \\
\hline Yuengert (1993) & US & $\begin{array}{l}\text { Stochastic cost } \\
\text { frontier }\end{array}$ & Life & $\begin{array}{l}\text { Premiums, } \\
\text { Annuities and } \\
\text { deposit funds }\end{array}$ & $0.50-0.65$ \\
\hline
\end{tabular}


In all those studies, ${ }^{1}$ it clearly appears that the efficiency levels are, on average, low and widely dispersed. This surprising result, compared with high efficiency levels usually reached by industrial firms, can be explained by a large market segmentation: the firms are highly specialized and they insure specific consumers because of adverse selection. Moreover, the prices paid by the insured persons depend on their own characteristics and the production technology can widely differ between companies. ${ }^{2}$

Other results were derived from those previous studies: efficiency increases with companies' scale; non-profit companies are more efficient than for-profit companies in Belgium and France while efficiency is independent of organizational form in the US; in the French insurance industry, efficiency appears negatively related to the reinsurance ratio while in Belgium an opposite result is obtained; in the US, regulatory factors do not influence efficiency.

In an international aggregate context, one cannot conjecture that similar results will appear. Indeed using aggregate instead of individual data means that the efficiency measures obtained not only reflect the ability of the managers to make the best use of resources but also the structural (economic, social and institutional) environment in which the firms operate. For this reason, we will control efficiency levels for some of those national characteristics.

The real difficulty of those efficiency studies lies in measuring the production of the insurance industry. Several authors have emphasized this problem. As Hornstein and Prescott (1991) explain "there is not even a conceptual definition of the output to guide the construction of a reasonable measure of its product. Without a conceptual measure, it is not clear what data should be collected and how they should be used to compute an output measure". Two alternatives are often suggested: on the one hand, premiums or incurred losses, and on the other hand, the number of policies contracted appropriately weighted. In most previous papers, premiums earned, losses and financial investments are used as a proxy for nominal output, in the awareness of the pitfalls of this approach well illustrated by Hornstein and Prescott (1991).

\section{Efficiency concept - DEA and Malmquist methods}

\subsection{Production set and technical efficiency}

In efficiency analysis the production function is interpreted not only as a relationship between inputs and outputs, but also as the frontier of a set called the production set. A point lying on the frontier is characteristically one that corresponds to the maximum achievable quantity of output for any given level of input, or also to the minimum required quantity of input for any given level of output. In Figure 1, a production set (shaded) and a production frontier (in bold) are represented in the case of one input and one output.

A distinction then naturally follows between productive activities in the production set. Every productive activity belonging to the frontier is defined as efficient while those lying below are said to be inefficient. To measure the extent to which a firm is inefficient, we use

${ }^{1}$ Except for Cummins and Weiss (1993) who find higher efficiency scores in the property liability industry. According to Grosskopf (1993), this could be partly due to the specification of the error term.

${ }^{2}$ See Fecher et al. (1991). 
the concept of distance: an inefficient activity is at some positive distance from the frontier. There are several ways of defining such a distance. Here we use the Farrell measure in input (Farrell, 1957). This measure is defined by the fraction of the input actually used that would be sufficient, given the output level, if the activity was efficient, i.e., if the quantity of input was the minimal one. For example, in Figure 1, the Farrell measure of $M_{t}$ is given by the ratio $\mathrm{Or} / \mathrm{Os}$. This measure of course is between zero and one.

Figure 1: The production frontier

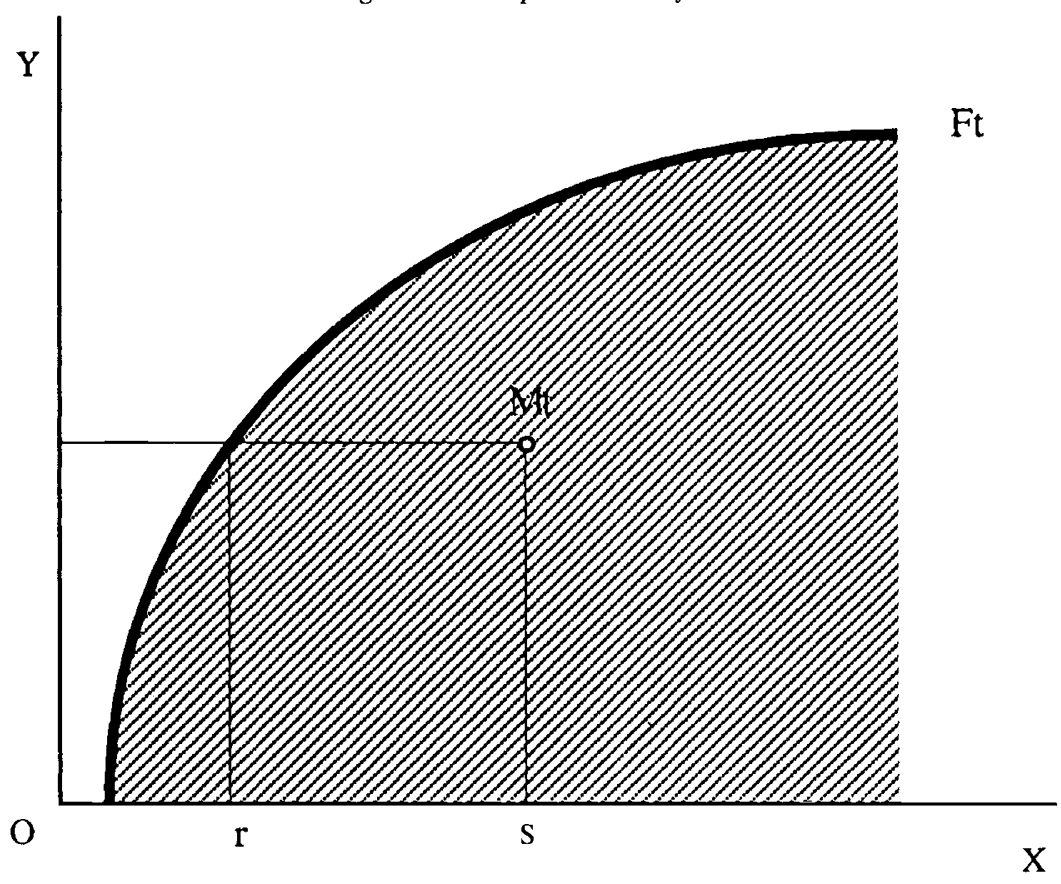

\subsection{The DEA method}

In general the production set is unknown but some techniques have been developed to construct it from cross section data that reports the outputs produced and the inputs used. The DEA (Data Envelopment Analysis) method, based upon Farrell's original article (1957), constructs an envelope of the observed input-output combinations by linear programming. ${ }^{3}$ It is a non-parametric method, that is, no explicit functional form with constant parameters is specified $a$ priori, but the points in the production set are supposed to satisfy some formal properties, e.g., free disposal and convexity. According to this method, the obtained production frontier is represented by a convex set of facets, i.e., the boundary of the free disposal convex hull of the data set.

3 The DEA method also gained from extensions by Charnes et al. (1978) and by Banker et al. (1984). See Seiford and Thrall (1990) for a survey of DEA techniques and for examples of the linear programming problems. 
In Figure 2, in the case of one input and one output, a data set is represented by points and the DEA envelope by OABCD curve. In this example, the observation $M$, is not efficient in comparison to the observations $B_{t}, C_{t}$ and $D_{t}$. Remark also that the production set is assumed to be convex from the point $A$, so that returns to scale are constant or decreasing for high levels of input. As the frontier includes the origin, increasing returns to scale appear for low levels of input. Moreover, the frontier is computed from a supporting subset of observations and is therefore sensible to extreme observation and measurement errors.

Figure 2: Approximation of a production frontier by the DEA method

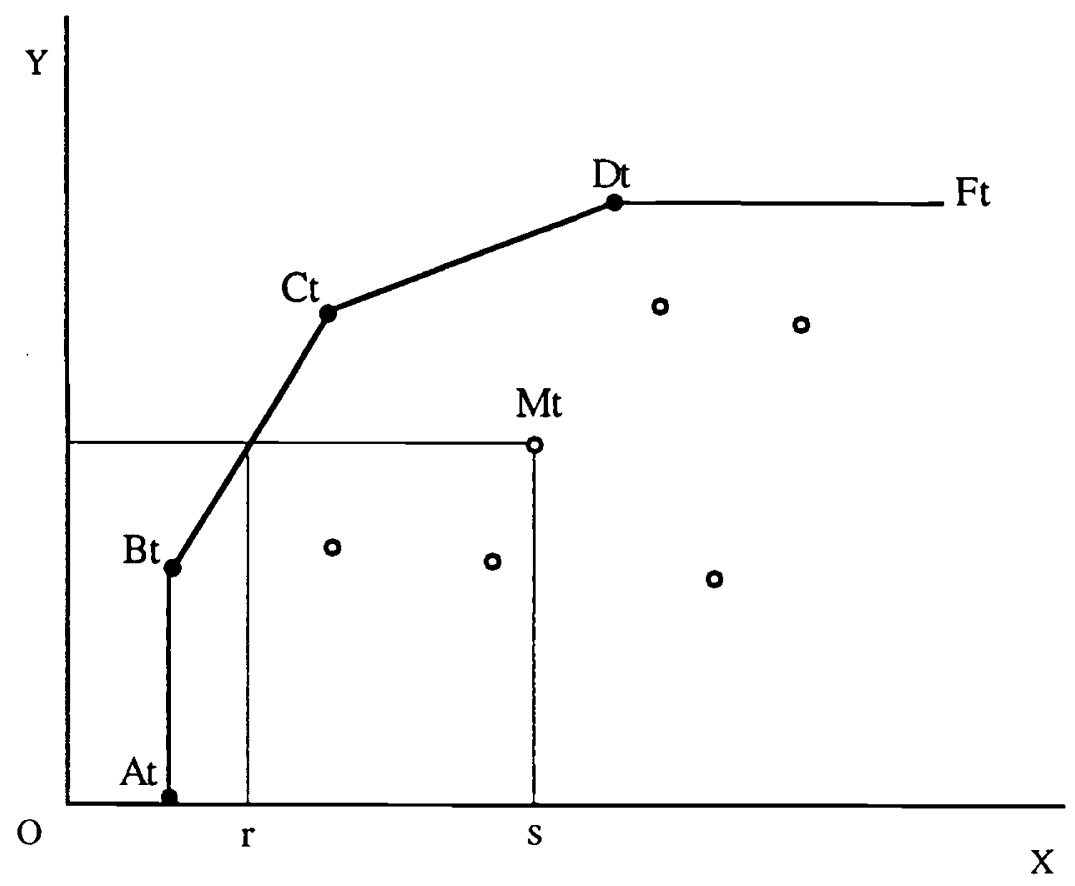

\subsection{The Malmquist index method}

One of the most interesting extensions of frontier analysis, when panel data are available, is its application to productivity growth measurement. From the preliminary work of Caves et al. (1982), Färe et al. (1992) a method based upon both the Malmquist index and the DEA approach has been introduced. The key idea is that a productivity change of one activity may be due to two components: an efficiency change or a technological change. Consequently, the Malmquist index of productivity change, $\mathrm{PC}$, is obtained as the product of two factors, that is, efficiency change, EC, and technological change, TC.

$$
\mathrm{PC}=\mathrm{EC} \times \mathrm{TC}
$$


The first factor, EC, is obtained as the ratio between efficiency scores achieved in periods $t$ and $t-1$. The second factor, TC, is a measure of the shift in the frontier over the two periods.

Figure 3: Measuring productivity change in the DEA context

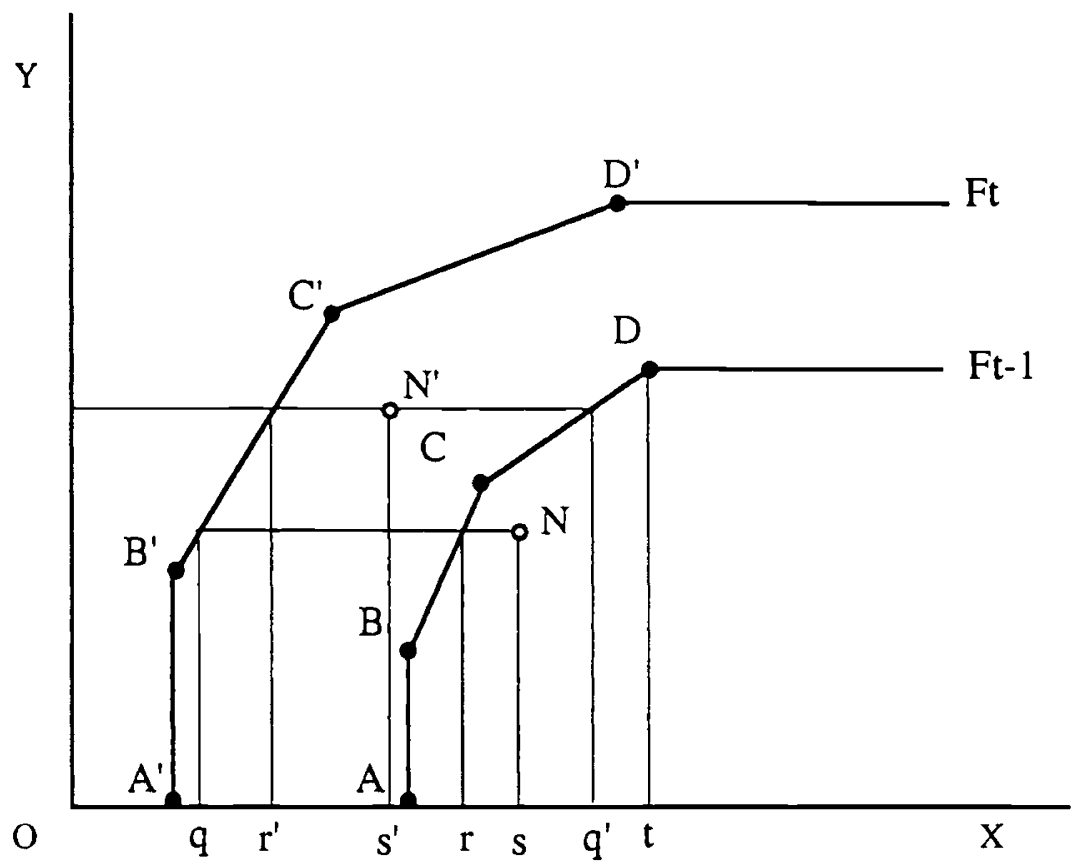

This can be illustrated with the help of the Figure 3. Let $F_{t}$ and $F_{t-1}$ be two frontiers, respectively constructed from the data for the period $t$ and the period $t-1$. In this figure, a shift of the frontier can be observed towards north-west, which can be interpreted as a technical progress since a higher level of output can be obtained with the same quantity of input. The influence of this frontier shift in the productivity change can be measured as the geometrical mean of the fraction that the minimal input necessary in $t$ represents vis-à-vis the minimal input necessary in $t-1$, given the output produced, for activity $N^{\prime}$ in $t$ and for activity $N$ in $t-1$. In the case of Figure 3, the Malmquist index between $t$ and $t-1$ is calculated as follows:

$$
\mathrm{PC}=\left[\frac{o r^{\prime}}{o s^{\prime}} / \frac{o r}{o s}\right] \times\left[\frac{o r}{o q} \times \frac{o q^{\prime}}{o r^{\prime}}\right]^{1 / 2}
$$

Three further remarks are in order at this stage. First, our example supposes the frontier shifts towards the north-west, i.e., a technical progress. However, the frontier can shift southeast. In this case there would be a technical regression but all the preceding explanations 
remain the same. Only the sign of technological change will be different. Second, for some activities, the measure of technical progress is sometimes difficult to calculate. For example, in Figure 3, if the activities $N^{\prime}$ move towards the north, the $s^{\prime} q^{\prime}$ distance can no longer be measured. In this case, one uses the technique initiated by Tulkens and Vanden Eeckaut (1993) which consists of measuring the distance $s^{\prime} t$. Third, to measure the productivity change, it is necessary that there be at least one observation for each country in each period. In this respect, we construct periods of three years. The average levels of input and output during this period of three years are used.

\section{Data and variable definitions}

The data used in this study have has made available over the period 1983-1991 from the OECD statistics on insurance. In 1985, the Insurance Committee started to collect data on insurance premiums and the number of insurance undertakings in member countries by sending a questionnaire concerning data for 1983. The first document gathering member countries contributions was put into general distribution in 1986. This document has since been updated and published annually and is now available on diskette (OECD, 1993).

These documents (and the diskettes) contain information on 24 countries. Some of them have been excluded from the analysis because of the unreliability of their data, that is, Australia, Austria, Denmark, Greece, Ireland, Luxemburg, Norway, Spain and Sweden. According to the available data, outputs are measured both by life and non-life net premiums at constant prices and in US dollars corresponding to 1985 purchasing power parities. Input is labor defined as total employment including intermediaries who sell insurance without being employed by the companies.

Table 2 gives a description of the main data used in this study. The insurance market of the different countries is very heterogeneous. This appears from the relative share of life and non-life premiums: non-life insurance overcomes life branch except in Finland, the United Kingdom and especially in Japan. This heterogeneity can also be perceived by looking at the wide dispersion across countries of basic characteristics such as reinsurance ratio (reinsurance accepted / gross premiums), market share in the OECD, foreign companies market share in the domestic market, life share (life net premiums / total net premiums) and average size of companies (number of employees per company). Those characteristics will be used below to explain part of efficiency differentials that we obtain.

\section{Results}

\subsection{Efficiency scores distribution}

The efficiency scores are given in Table 3. It appears that the dispersion in efficiency levels is quite important. Average efficiency is around $70 \%$. Most of the industrialized countries (United States, United Kingdom, France and Germany) get a leading position (except Japan and Canada). ${ }^{4}$ Far behind are two countries (Finland and Portugal) whose efficiency scores are very low. This large dispersion in efficiency levels can be partly explained by mismanagement and market segmentation as observed with micro data. However in this international context, the efficiency scores are also determined by structural constraints.

\footnotetext{
${ }^{4}$ Iceland reaches full efficiency because the country is quite small and consequently not comparable.
} 


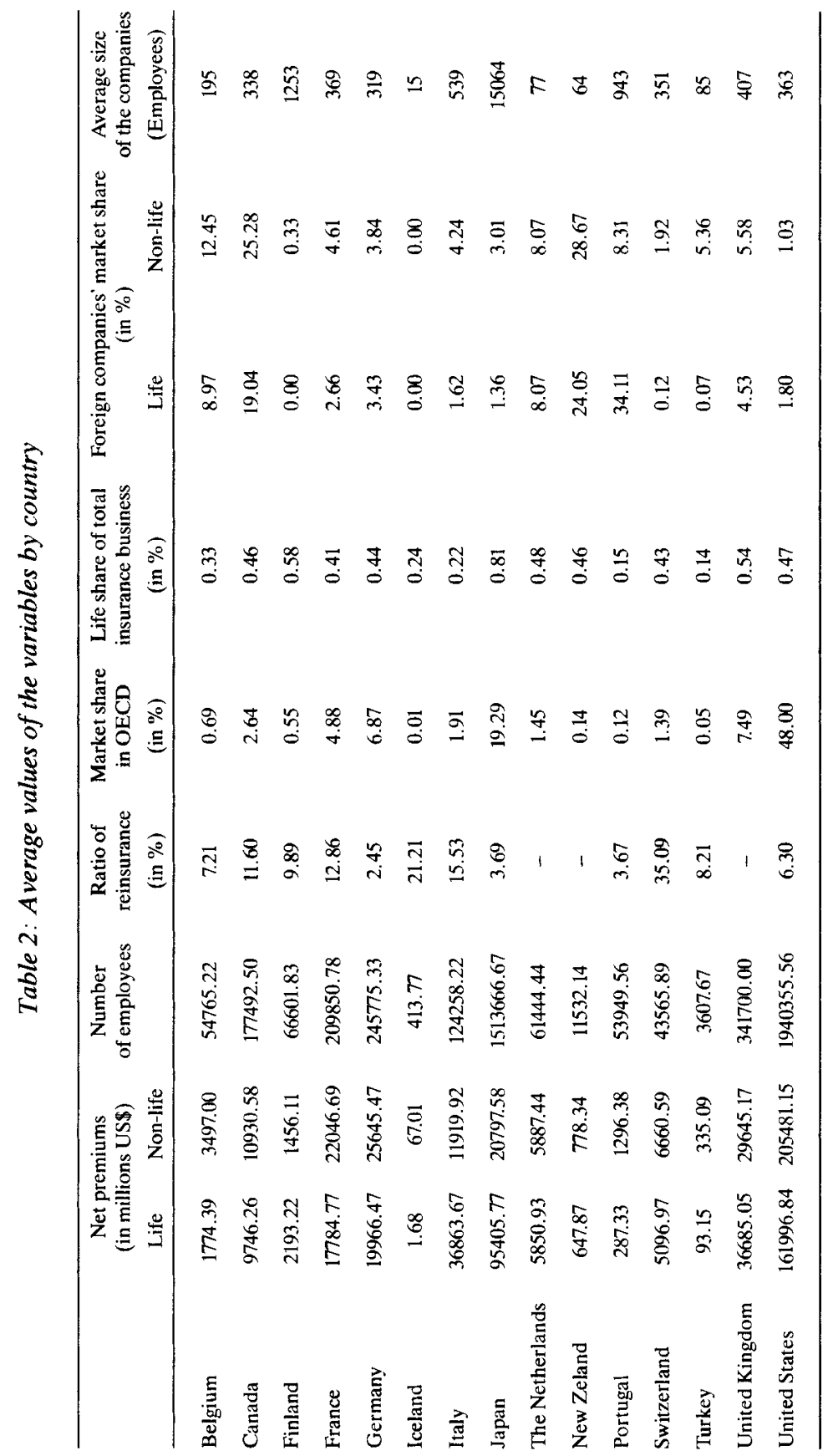


This explains that the US present full efficiency in the aggregate context and low performance in firms' studies. Remark also the poor performance of Belgium as compared with France which confirms earlier research achieved with micro-data (Delhausse, et al., 1992).

A second step in the analysis is to study the trends in terms of productivity changes. These results are presented in Table 3 . One remarks that productivity growth during the period analyzed is widely dispersed but generally strong. The highest rate is reached by Finland $(17 \%)$. Four countries follow: Turkey, Japan, The Netherlands and the United Kingdom with an average annual rate of productivity higher than $7 \%$.

Technological progress generally accounts for the largest part of growth in productivity. Finland, Turkey and Japan display rates of efficiency growth higher than $5 \%$. Note that efficiency growth means that insurance industries do better within the OECD production frontier. We can interpret this as a kind of catching-up effect of the leader countries. This can explain why Finland, Turkey and Japan, characterized by low efficiency levels, realize very high gains.

Technological progress reflects a shift of the production frontier. Table 3 shows that some countries are more dynamic in the adoption of new technology. This is the case for the United Kingdom, France, Germany and Finland with an average annual rate higher than 5\% over the period considered. We observe a low technological regress in Belgium and Portugal which is, however, more than compensated by efficiency gains.

It is generally admitted that the productivity gains in the insurance industry are low, usually below those of the whole economy. This can be explained by the highly laboristic nature of the insurance production process which prevents the introduction of new technology. As Baumol (1991) writes: "the direct personal involvement of the supplier is an essential feature of the service itself or a major determinant of its quality". Our results seem to contradict this assertion. This calls for three remarks.

Table 3: Efficiency scores and Malmquist index decomposition (average values over 1983-1991 period)

\begin{tabular}{lcccc}
\hline Countries & $\begin{array}{c}\text { Efficiency } \\
\text { level }\end{array}$ & $\begin{array}{c}\text { Productivity } \\
\text { change }\end{array}$ & $\begin{array}{c}\text { Efficiency } \\
\text { change }\end{array}$ & $\begin{array}{c}\text { Technological } \\
\text { change }\end{array}$ \\
\hline Iceland & 1.00 & 1.018 & 0.999 & 1.019 \\
United States & 1.00 & 1.043 & 1.015 & 1.027 \\
Switzerland & 0.98 & 1.010 & 1.002 & 1.007 \\
France & 0.96 & 1.058 & 0.996 & 1.061 \\
United Kingdom & 0.95 & 1.074 & 0.997 & 1.077 \\
Germany & 0.91 & 1.031 & 0.980 & 1.052 \\
The Netherlands & 0.78 & 1.079 & 1.031 & 1.046 \\
Italy & 0.71 & 1.041 & 1.010 & 1.030 \\
Japan & 0.59 & 1.086 & 1.066 & 1.018 \\
Turkey & 0.55 & 1.088 & 1.078 & 1.009 \\
New Zealand & 0.51 & 1.027 & 0.992 & 1.047 \\
Canada & 0.50 & 1.022 & 0.976 & 0.989 \\
Belgium & 0.39 & 1.025 & 1.035 & 1.052 \\
Finland & 0.30 & 1.174 & 1.116 & 0.992 \\
Portugal & 0.15 & 1.040 & 1.048 & 1.031 \\
Means & 0.70 & 1.055 & 1.023 & 2.54 \\
Coef. of variation & 39.64 & 4.10 & 3.88 & - \\
Numb. of observations & 126 & - & - & \\
\hline
\end{tabular}


First, our model of productivity change measurement does not take into account capital input. Despite a very low capital intensity, the rate of growth of capital stock in insurance industry has been higher than the average rate reached by other sectors. More precisely, computer investments have been very high during the eighties (see Wolff, 1991). This new information technology has improved performance in companies' administrative activities. ${ }^{5}$ In the same respect, Wolff (1991) explains the low rate of productivity growth in the early eighties with the high costs of adjustment involved in the growth of capital formation.

Second, Kessler (1991) notices that the US insurance industry has experienced lower productivity gains than the European and Japanese industries. Moreover, he points out that the way the output is measured is essential.

A third argument can be put forward. In most of the OECD countries, a large phenomenon of market deregulation is observed. This could involve an efficiency growth and therefore an increase in productivity.

\subsection{Explaining the efficiency scores}

As mentioned above, the insurance markets of the OECD countries are very heterogeneous. The third step of our analysis is to determine whether the efficiency differences can be explained by the structural peculiarities of national markets. Indeed, if we were controlling these national characteristics, the variance of our efficiency scores could be reduced. The data base provides some information concerning those structural characteristics such as reinsurance, foreign entrance, market size...6

In this respect, we must note that efficiency scores belong to the interval $(0,1)$ with some concentration at the upper bound. This makes ordinary least squares regression analysis an inappropriate technique. To resolve this problem, we transform the dependant variable into logarithms and we suppose it is censored at zero to apply a tobit model. As explanatory variables we use insurance industries' characteristics presented in Table 2 transformed into logarithms.

The estimated parameters of the tobit model are given in Table $4 .{ }^{7}$ Some results have to be underlined.

\footnotetext{
${ }^{5}$ Baumol (1991) defines the service delivered by an insurance company as a bundle of services: automobile repair, medical treatment, awards made by juries, litigation costs... All are very laborintensive with the exception of the administrative activities, which take advantage of the high rate of computerization.

${ }^{6}$ Another interesting variable is the level of regulation. Fecher and Pestieau (1993) use it in their study of efficiency in the OECD financial services.

7 The $R^{2}$ obtained in a previous ordinary least square step indicates that all the characteristics taken together explain $70 \%$ of the estimated efficiency variance.
} 
Table 4: Factors explaining technical efficiency levels (EFF)

(Tobit coefficients 1)

Variables

Parameters

- Intercept

$-1.151^{*}$

- Ratio of reinsurance accepted

- Market share in OECD countries

- Life share of total insurance business

- Foreign companies' market share

(life insurance)

- Foreign companies' market share

(non-life insurance)

- Mean size of the companies

- Trend

$\cdot \sigma$

- Number of observations

** Statistically significantly different from zero at the $1 \%$ level.

* Statistically significantly different from zero at the $5 \%$ level.

1. Standard deviations are in brackets.

First, it appears that countries with high reinsurance rates tend to be more efficient. Coverage through reinsurance would be an incentive to be performant. This confirms previous results obtained with individual Belgian companies' data. However, note that the opposite result was observed in the French insurance market.

Second, market share in OECD countries fosters efficiency. Some learning by doing processes related to the country size could partly explain this result. The micro unit studies also underline this positive relation.

Third, performance is negatively related to the share of life insurance. This can be explained by the highly national specific characteristics of this branch which involve a larger dispersion of efficiency levels between countries.

Because of these peculiarities, the foreign entrance in the life branch is made difficult and consequently can only appear in poorly performant countries. Our results confirm this relation: a negative significant coefficient is associated to the variable representing foreign entrance in life branch. In the non-life branch characterized by a more homogenous product, the relation is negative but not significant. 
Finally, a negative relation appears between the mean size of the companies and the efficiency level. That probably means there are some diseconomies of scale at the company level. However, the debate about the returns to scale in the insurance industry remains open. Until now no definitive conclusion can be drawn from earlier studies. A brief summary of the debate is given by Suret (1991).

\section{Conclusion}

The purpose of the paper is to measure technical efficiency levels in 15 OECD insurance industries over the period 1983-1991 and to decompose productivity changes into technical progress and efficiency variations. Average efficiency levels appeared rather high and dispersed. Moreover, we have shown that the growth in productivity observed in all countries is essentially imputable to improvements in technical progress.

We then tried to see whether some structural national characteristics of insurance markets can partly explain the differentials in efficiency levels across countries. Reinsurance rates and market share in OECD both seem to favor efficiency level.

The study was a step towards a comprehensive efficiency comparative study of the OECD insurance market, especially desirable in this period of increasing integration and deregulation of the market.

\section{REFERENCES}

BAUMOL, W. J. (1991), “Technological imperatives, productivity and insurance costs”, The Geneva Papers on Risk and Insurance, 59, pp. 154-165.

CAVES, D., CHRISTENSEN, L. and DIEWERT, E. (1982), “The economic theory of index numbers and the measurement of input, output, and productivity", Econometrica, 50, pp. 1393-1414.

CHARNES, A., COOPER, W. W. and RHODES, E. (1978), "Measuring the efficiency of decision making units", European Journal of Operational Research, 2, pp. 429-444.

CUMMINS, J. D. and WEISS, M. A. (1993), "Cost efficiency in the property-liability insurance industry", Journal of Banking and Finance, 17, 2-3, pp. 463-481. 
DELHAUSSE, B., FECHER, F., PERELMAN, S. and PESTIEAU, P. (1995), "Measuring productive performance in the non-life insurance industry: the case of French and Belgian markets", Tijdschrift voor economic en management, 40, pp. 47-69.

DONNI, O. and HAMENDE, V. (1993), "Performance des sociétés belges d'assurance", Annales de l'Economie Publique, Sociale et Coopérative, 64, 3, pp. 419-437.

FÄRE, R., GROSSKOPF, S., LINDGREN, B. and ROOS, P. (1992), "Productivity changes in Swedish pharmacies 1980-1989: a non-parametric Malmquist approach", Journal of Productivity Analysis, 3, pp. 85-101.

FARELL, M. J. (1957), "The measurement of productive efficiency", Journal of the Royal Statistical Society, A 120, pp. 253-281.

FECHER, F. and PESTIEAU, P. (1993), "Efficiency and competition in OECD financial services", in The measurement of productive efficiency: techniques and applications, H. Fried, $\mathrm{K}$. Lovell and $\mathrm{S}$. Schmidt (ed.), Oxford University Press, Oxford.

FECHER, F., KESSLER, D., PERELMAN, S. and PESTIEAU, P. (1993), "Productive performance of the French insurance industry", Journal of Productivity Analysis, 4, pp. 77-93.

FECHER, F., PERELMAN, S. and PESTIEAU, P. (1991), "Scale economies and performance in the French insurance industry", The Geneva Papers on Risk and Insurance, 60, pp. 315-326.

FRIED, H. O., LOVELL, C. A. K. and SCHMIDT, S. S. (eds.) (1993), The measurement of productive efficiency: Techniques and applications, Oxford University Press, Oxford.

GARDNER, L. A. and GRACE, M. F. (1993), "X-efficiency in the U.S. life insurance industry", Journal of Banking and Finance, 17, 2-3, pp. 497-510.

GROOSKOPF, S. (1993), "Discussants' comments on Cummins and Weiss, Yuengert, and Grace and Gardner", Journal of Banking and Finance, 17, 2-3, pp. 511-513.

HORNSTEIN, A. and PRESCOTT, E. C. (1991), "Measures of the insurance sector output", The Geneva Papers on Risk and Insurance, 59, pp. 191-206.

KESSLER, D. (1991), "A comment on technological imperatives, productivity, and insurances costs", The Geneva Papers on Risk and Insurance, 59, pp. 170-172.

MADDALA, G. S. (1983), Limited-dependent and qualitative variables in econometrics, Econometric Society Monographs in Quantitative Economics, Cambridge University Press, Cambridge.

OECD (1993), "Insurance statistics 1983-1991”, Diskettes, Paris.

SEIFORD, L. M. and THRALL R. M. (1990), "Recent developments in DEA", Journal of Econometrics, 46, pp. 7-38.

SURET, J. M. (1991), "Scale and scope economies in the Canadian property and casualty insurance industry", The Geneva Papers on Risk and Insurance, 59, pp. 236-256.

TULKENS, H. and VAN DEN EECKAUT, P. (1993), "Non-parametric efficiency, progress and regress, measures for panel data: methodological aspects", Working Paper No. 38, University of Munich, Munich.

WOLFF, E. N. (1991), "Productivity growth, capital intensity, and skill levels, in the U.S. insurance industry, 1948-1986", The Geneva Papers on Risk and Insurance, 59, pp. 173-190.

YUENGERT, A. M. (1993), "The measurement of efficiency in life insurance: estimates of a mixed normal-gamma error model", Journal of Banking and Finance, 17, 2-3, pp. 483-496. 